\title{
Establishment and Characterization of Orthotopic Mouse Models for Human Uveal Melanoma Hepatic Colonization
}

\author{
Shinji Ozaki, ${ }^{* \dagger}$ Raja Vuyyuru, ${ }^{\ddagger}$ Ken Kageyama, ${ }^{\star}$ Mizue Terai, ${ }^{*}$ Masahiro Ohara, ${ }^{*}$ Hanyin Cheng, ${ }^{\S}$ Tim Manser,
} Michael J. Mastrangelo, ${ }^{*}$ Andrew E. Aplin, ${ }^{\S}$ and Takami Sato*

\begin{abstract}
From the Departments of Medical Oncology, * Microbiology and Immunology, ${ }^{\ddagger}$ and Cancer Biology, ${ }^{\S}$ Kimmel Cancer Center, Thomas Jefferson University, Philadelphia, Pennsylvania; and the Department of Breast Surgery, ${ }^{\dagger}$ National Hospital Organization, Kure Medical Center/Chugoku Cancer Center, Kure-shi, Japan
\end{abstract}

\author{
Accepted for publication \\ September 17, 2015. \\ Address correspondence to \\ Takami Sato, M.D., Ph.D., \\ Department of Medical \\ Oncology, Thomas Jefferson \\ University, 1015 Walnut St., \\ Ste. 1024, Philadelphia, \\ PA 19107. E-mail: takami. \\ sato@jefferson.edu.
}

\begin{abstract}
Uveal melanoma (UM) is a rare type of melanoma, although it is the most common primary ocular malignant tumor in adults. Nearly one-half the patients with primary UM subsequently develop systemic metastasis, preferentially to the liver. Currently, no treatment is effective for UM hepatic metastasis, and the prognosis is universally poor. The main challenge in designing a treatment strategy for UM hepatic metastasis is the lack of suitable animal models. We developed two orthotopic mouse models for human UM hepatic metastases: direct hepatic implantation model (intrahepatic dissemination model) and splenic-implantation model (hematogenous dissemination model) and investigated the tumorgenesis in the liver. A human UM cell line, established from a hepatic metastasis and nonobese diabetic severe combined immunodeficient $\gamma$ mice, were used for development of in vivo tumor models. In the direct hepatic implantation model, a localized tumor developed in the liver in all cases and intrahepatic dissemination was subsequently seen in about one-half of cases. However, in the splenic implantation model, multiple hepatic metastases were observed after splenic implantation. Hepatic tumors subsequently seeded intra-abdominal metastasis; however, lung metastases were not seen. These findings are consistent with those observed in human UM hepatic metastases. These orthotopic mouse models offer useful tools to investigate the biological behavior of human UM cells in the liver. (Am J Pathol 2016, 186: 43-56; http://dx.doi.org/10.1016/j.ajpath.2015.09.011)
\end{abstract}

Uveal melanoma (UM) is a rare form of melanoma but remains the most common primary ocular malignant tumor in adults. The annual incidence of the disease is 6.3 per million among whites, 0.9 among Hispanics, and 0.24 among blacks. ${ }^{1}$ In North America, the incidence has been stable, and approximately 1500 cases per year are newly diagnosed. ${ }^{2}$ Although the diagnostic modalities and the local treatments have improved over the past decades, with increased use of nonsurgical methods such as radiation for preservation of the eye, the mortality has remained unchanged because of the lack of effective treatments for metastatic disease. The eye lacks lymphatics, and metastatic spread exclusively occurs by the hematogenous route, especially to the liver. Up to $50 \%$ of patients with UM develop systematic metastasis after initial diagnosis and the treatment of the primary site. In patients that develop metastatic disease, the liver is the site of dissemination in $70 \%$ to $90 \%$ of cases. ${ }^{3-5}$ The site of metastasis affects length of

Supported by Bonnie Kroll Research Fund, Mark Weinzierl Research Fund, and the Eye Melanoma Research Fund at Thomas Jefferson University. Studies in the Aplin's laboratory were supported by NIH grant R01 GM067893. This project was also funded by a Dean's Transformative Science Award, a Thomas Jefferson University Programatic Initiative Award.

Portions of this work were presented at the American Association for Cancer Research (AACR) annual meetings, April 6-10, 2013, Washington, DC, and April 18-22, 2015, Philadelphia, PA.

Disclosures: None declared. 
survival. The median survival of the patients with only extrahepatic metastasis is approximately 19 to 28 months with a 1-year survival rate of approximately $76 \%{ }^{4,6,7}$ In contrast, the median survival of patients with hepatic metastasis is approximately 4 to 6 months with a 1-year survival rate of approximately $10 \%$ to $15 \%$. ${ }^{8,9}$ Currently, no standard treatment is able to prolong the survival of the patients with hepatic metastases; therefore, investigation on the pathogenesis of hepatic metastasis and the development of effective treatments for metastatic lesions in the liver are urgently needed to improve the prognosis of patients having this disease. In vivo models for human UM hepatic metastasis are essential to investigate its biological behavior and to test therapeutic strategies. Current models are limited by the use of cell lines derived from primary UM lesions and their growth in the subcutaneous tissue. Considering the hepatic tropism of UM, an orthotopic hepatic tumor model is essential to investigate the tumor progression and to test treatment efficacies in the liver microenvironment. ${ }^{10,11}$ The evolution of UM hepatic metastasis consists of two phases: hematogenous spread of UM cells to the liver and intrahepatic growth and subsequent dissemination of the UM cells. In this study, we have developed two orthotopic mouse models of human UM hepatic metastasis with the use of a human UM cell line established from a hepatic metastasis (TJU-UM001) injected into nonobese diabetic severe combined immunodeficient $\gamma$ (NSG) mice. The resulting lesions were characterized by macroscopic and histologic examinations. Moreover, we have generated a td-Tomato fluorescent protein-expressed UM cell line to permit noninvasive, quantitative, and temporal analysis of UM tumor colonization in the liver.

\section{Materials and Methods}

\section{UM Cell Line and Culture Conditions}

A human UM cell line, TJU-UM001, was established from a UM hepatic metastasis and characterized in our laboratory. Cells were maintained in RPMI 1640 (Corning Cellgro; Mediatech, Manassas, VA) supplemented with $10 \%$ fetal bovine serum, $1 \%$ nonessential amino acid, $2 \%$ L-glutamine, $1 \%$ HEPES, and $5000 \mathrm{IU}$ penicillin and $5000 \mu \mathrm{g} / \mathrm{mL}$ streptomycin in a humidified atmosphere that contained $5 \% \mathrm{CO}_{2}$ at $37^{\circ} \mathrm{C}$. TJU-UM001 harbors a GNAQ ${ }^{\mathrm{Q} 209 \mathrm{P}}$ mutation but lacks BRAF ${ }^{\mathrm{V} 600 \mathrm{E} / \mathrm{D} / \mathrm{K}}$ and KIT exon 11 mutations observed in cutaneous and mucosal melanoma. ${ }^{12,13}$ These findings are consistent with the typical phenotype of UM. ${ }^{14-18}$ Somatic mutations in the gene encoding BRCA1-associated protein 1 (BAP1) ${ }^{19}$ were absent. This cell line produces small amounts of insulin growth factor (IGF) ${ }^{20}$ and hematopoietic growth factor (HGF; $10.1 \mathrm{pg} / \mathrm{mL} / 24$ hours; unpublished data) when cultured in vitro.

\section{Generation of tdTomato-Expressing UV Cell Line}

The tdTomato lentiviruses were packaged in 293FT cells, as previously described. ${ }^{21}$ Briefly, $3 \mu \mathrm{g}$ of lentivirus construct
FutdTW (Plasmid 22478; Addgene, Cambridge, MA) and $3 \mu \mathrm{g}$ each of pLP1, pLP2, and pLP-vesicular stomatitis virus glycoprotein (VSVG) were transfected into 293FT cells with the use of Fugene HD (Roche, Basel, Switzerland) according to the manufacturer's instructions. The tdTomato lentiviral particles were collected 72 hours after transfection and concentrated with PEG-IT virus precipitation solution (NC9846201; Fisher Scientific International, Inc., Hampton, NH). To infect UM001 cells, $3 \times 10^{5}$ cells/well were plated in 6 -well plates. The next day, $20 \mu \mathrm{L}$ of concentrated virus was added. Transfection efficacy was measured by BD FACS Calibur flow cytometer and an inverted fluorescence microscope with suitable filter (Eclipse Ti; Nikon Instrument, Inc., Melville, NY) to tdTomato fluorescence.

Flow Cytometric Analysis on Melanoma Markers, Growth Factors, and Growth Factor Receptors on TJU-UM001

\section{Antibodies}

Primary antibodies against representative melanoma markers, including human melanosome (clone: HMB45; M0634; Dako, Carpentaria, CA), human Melan-A (clone: A103; M7196; Dako), and secondary antibodies, fluorescein isothiocyanate (FITC)-conjugated were used. Isotype-matched IgG antibodies were used as a control. For antibodies against the cell surface growth receptors, human c-Met $\alpha$ subunit IgG1 $\kappa$, FITC-conjugated (11-8858-41; eBiosciences, San Diego, CA), human IGF-1R $\alpha$ subunit IgG1 $\kappa$, phycoerythrin (PE)-conjugated (560934; BD Biosciences Pharmigen, San Diego, CA) antibodies were used. Isotype-matched IgG antibodies, FITC-, or PE-conjugated were used as a control. For vascular endothelial growth factor (VEGF) signaling, primary antibody against VEGF (M7273; Dako) and secondary antibody, FITC-conjugated; VEGF receptor 2 (VEGFR2) subunit IgG1 к, PE-conjugated (359903; BioLegend, San Diego, CA); and primary antibody against phospho-VEGFR2 (2478; Cell Signaling Technology, Beverly, MA) and secondary antibody, PE-conjugated were used. Isotype-matched IgG antibodies, FITC-, or PE-conjugated were used as a control. The detailed information on antibodies used in our experiments is listed in Table 1.

\section{Procedures for Flow Cytometric Analysis}

Cells were grown to near confluence, harvested with $2 \times$ phosphate-buffered saline-EDTA, washed with cold fluorescence-activated cell sorting (FACS) buffer $(0.1 \%$ BSA, $0.1 \%$ sodium azide, $0.035 \%$ sodium bicarbonate, and 0.98\% Hanks Balanced Salt in distilled water, $\mathrm{pH}$ 7.4), and resuspended in cold FACS buffer to achieve single-cell suspension. For the staining of intracellular antigens, cells were fixed in $50 \%$ ethanol at $4{ }^{\circ} \mathrm{C}$ for 10 minutes and permeabilized with $0.1 \%$ Saponin-phosphate-buffered saline for 10 minutes at room temperature. Ten microliter of each primary or isotype-matched antibody, FITC- or PE-conjugated 
Table 1 Description of the Used Primary Antibodies for Flow Cytometric Analysis and Immunohistochemistry

\begin{tabular}{|c|c|c|c|c|c|c|c|}
\hline Antigen & Host & $\begin{array}{l}\text { Clone } \\
\text { number }\end{array}$ & Reactivity & Product & Distributor & $\begin{array}{l}\text { Dilution } \\
\text { rate }\end{array}$ & Tissue specimen \\
\hline \multicolumn{8}{|l|}{ Flow cytometric analysis } \\
\hline Melan-A & Mouse, monoclonal & A103 & Human & M7196 & Dako & NA & NA \\
\hline c-Met & Rat, monoclonal & $11-8858-41$ & Human & ab51067 & eBiosciences & NA & NA \\
\hline IGF-1R & Mouse, monoclonal & 560934 & Human & $790-4346$ & $\begin{array}{c}\text { BD Biosciences } \\
\text { Pharmigen }\end{array}$ & NA & NA \\
\hline VEGFR2 & Rabbit, monoclonal & 7D4-6 & Human & 359903 & BioLegend & NA & NA \\
\hline Phospho-VEGF Receptor 2 & Rabbit, monoclonal & $19 \mathrm{~A} 10$ & $\begin{array}{l}\text { Human, } \\
\text { Mouse }\end{array}$ & 2478 & Cell Signaling & NA & NA \\
\hline \multicolumn{8}{|l|}{ Immunohistochemistry } \\
\hline Melanosome & Mouse, monoclonal & HMB45 & Human & M0634 & Dako & $1: 50$ & Paraffin embedded \\
\hline Phospho-c-Met & Rabbit, monoclonal & $\mathrm{D} 26$ & $\begin{array}{l}\text { Human, } \\
\text { Mouse, Rat }\end{array}$ & 3077 & Cell Signaling & $1: 150$ & Paraffin embedded \\
\hline IGF-1R & Rabbit, monoclonal & G11 & Human & $790-4346$ & Ventana & $1: 1.5$ & Paraffin embedded \\
\hline Phospho-IGF-1R & Rabbit, polyclonal & none & Human, Mouse & Sc-101703 & Santa Cruz & $1: 500$ & Paraffin embedded \\
\hline CD31 & Rabbit, polyclonal & none & Human, Mouse & ab28364 & Abcam & $1: 100$ & Paraffin embedded \\
\hline Laminin & Mouse, monoclonal & LAM-89 & Human & L8271 & Sigma-Aldrich & $1: 1000$ & Paraffin embedded \\
\hline VEGF & Mouse, monoclonal & VG1 & Human & M7273 & Dako & $1: 50$ & Paraffin embedded \\
\hline VEGF Receptor 2 & Rabbit, monoclonal & 55B11 & Human, Mouse & 2479 & Cell Signaling & $1: 250$ & Paraffin embedded \\
\hline Phospho-VEGF Receptor 2 & Rabbit, monoclonal & $19 \mathrm{~A} 10$ & Human, Mouse & 2478 & Cell Signaling & $1: 100$ & Paraffin embedded \\
\hline
\end{tabular}

IGF-1R, insulin growth factor 1 receptor; NA, not applicable; VEGF, vascular endothelial growth factor.

were added to the $100-\mu \mathrm{L}$ cell suspension in FACS buffer and incubated at $4{ }^{\circ} \mathrm{C}$ for 30 minutes. In cases that used nonconjugated primary antibodies, cells were washed with cold FACS buffer after staining with primary antibody, and 5 or $10 \mu \mathrm{L}$ of secondary antibody, FITC- or PE-conjugated was added to the $200-\mu \mathrm{L}$ cell suspension in FACS buffer. Cells were then incubated at $4^{\circ} \mathrm{C}$ for 30 minutes according to the manufacturer's instructions. After washing, cells were analyzed with a BD FACS Calibur flow cytometer (BD Biosciences, Franklin Lakes, NJ). Data were analyzed by FlowJo software version 9.6 (Tree Star, Inc., Ashland, OR).

\section{Histology and Immunohistochemistry}

After extirpation of a total liver, liver specimens were promptly divided and fixed with cold $4 \%$ paraformaldehyde (Wako Pure Chemical Industries, Ltd., Osaka, Japan) overnight and embedded in paraffin for hematoxylin and eosin (H\&E) staining or immunohistochemical (IHC) staining. Paraffin-embedded tissues were cut into 5 - $\mu \mathrm{m}$ tissue sections with the use of a microtome. After drying overnight at room temperature, deparaffinization and rehydration were performed (100\% xylene four times for 2 minutes each, $100 \%$ ethanol two times for 2 minutes each, and distilled water for 1 minute). Histopathologic evaluation was performed with hematoxylin or H\&E staining. As for immunohistochemistry of the tumors, the following markers were investigated: i) melanoma markers melanosome (Clone HMB45), Melan-A
(Clone: A103), or S100; ii) cell surface growth factor receptors: c-Met, phospho-c-Met, IGF-1R, and phospho-IGF$1 \mathrm{R}$; iii) vascular structures: CD31 for endothelial marker for blood vessels, human laminin for basement membrane for vasculogenic mimicry; and iv) VEGF signaling: VEGF, VEGFR2 (cell surface and cytoplasm), and phosphoVEGFR2 (cytoplasm). The sources of specific antibodies for these markers and their dilution rates are listed in Table 1. Isotype-matched control antibodies were purchased from the same manufacturers for individual antibodies.

Antigen retrieval was performed by a heat-mediated method (heated for 20 minutes in Tris-EDTA Buffer at $\mathrm{pH}$ 9 in boiling water) for all targeted antigens except for human laminin. An enzymatic method was used for human laminin staining, including incubation for 5 minutes at room temperature with proteinase K (S3020; Dako). For endogenous peroxidase and alkaline phosphatase activity, the sections were blocked for 10 minutes with dual endogenous enzyme block (S2003; Dako). For blocking, sections were incubated for 20 minutes with diluted blocking sera from species in which the secondary antibody was made; S-1000 or S-2000 (Vector Laboratories, Burlingame, CA).

Tissue sections were incubated overnight at $4^{\circ} \mathrm{C}$ with each primary antibody at predetermined dilution. Sections were then incubated for 30 minutes at room temperature with diluted biotinylated secondary antibody solution (BA-1300; Vector Laboratories). After washing slides, sections were 
Table 2 Incidence of Intrahepatic Tumor and Extrahepatic Tumor in Direct Hepatic Implantation Model

\begin{tabular}{|c|c|c|c|c|}
\hline Rates for tumor incidence $[n / N(\%)]$ & & $\begin{array}{l}\text { Size of tumor in } \\
\text { implantation } \\
\text { site (mm), } \\
\text { [means } \pm \text { SD (range)] }\end{array}$ & $\begin{array}{l}\text { Number of } \\
\text { vascular } \\
\text { invasion } \\
\text { [means } \pm \text { SD (range)] }\end{array}$ & $\begin{array}{l}\text { Number of } \\
\text { intrahepatic } \\
\text { dissemination } \\
\text { [means } \pm \text { SD (range)] }\end{array}$ \\
\hline \multicolumn{5}{|l|}{4 Weeks $(n=2)$} \\
\hline \multicolumn{5}{|l|}{ Tumor formation } \\
\hline \multicolumn{5}{|l|}{ Intrahepatic tumor } \\
\hline Intrahepatic dissemination & $0 / 2(0)$ & & & \\
\hline \multicolumn{5}{|l|}{ Extrahepatic tumor } \\
\hline Peritoneum & $1 / 2(50)$ & & & \\
\hline \multicolumn{5}{|l|}{8 Weeks $(n=6)$} \\
\hline \multicolumn{5}{|l|}{ Tumor formation } \\
\hline \multicolumn{5}{|l|}{ Extrahepatic tumor } \\
\hline Peritoneum & $4 / 6(66.7)$ & & & \\
\hline \multicolumn{5}{|l|}{12 Weeks $(n=6)$} \\
\hline \multicolumn{5}{|l|}{ Tumor formation } \\
\hline \multicolumn{5}{|l|}{ Intrahepatic tumor } \\
\hline Hepatic tumor in implantation site & $6 / 6(100)$ & $8.5 \pm 4.7(2-15)$ & $3.7 \pm 1.8(1-5)$ & $7.0 \pm 13.8(0-35)$ \\
\hline Satellite nodule & $6 / 6(100)$ & & & \\
\hline Intrahepatic dissemination & $4 / 6(66.7)$ & & & \\
\hline \multicolumn{5}{|l|}{ Extrahepatic tumor } \\
\hline Peritoneum & $4 / 6(66.7)$ & & & \\
\hline Regional lymph node of the stomach & $1 / 6(16.7)$ & & & \\
\hline
\end{tabular}

Cell number to implant is $1.00 \times 10^{6}$ cells $/ 20 \mu \mathrm{L}$.

incubated for 30 minutes at room temperature with VECSTATIN ABC-AP or Elite ABC reagent (AK-5000, PK6100; Vector Laboratories). After washing, sections were incubated for 20 to 30 minutes in alkaline phosphatase substrate solution with the use of Vector Red (SK-5100) or Blue (SK-5300) or 10 minutes in peroxidase substrate solution with the use of Vector Nova RED (SK-4800) until desired stain intensity developed. Sections were then counterstained with Mayer's Hematoxylin (TA-060-MH; Thermo Scientific, Paisley, UK), cleared with $100 \%$ ethanol and Hisoclear-II (HS-202; National Diagnostics, Grove City, PA) for $5 \mathrm{mi}$ nutes twice, respectively, and mounted with Vecta Mount (H-5000; Vector Laboratories).

\section{Mice}

NOD.Cg-Prkdc ${ }^{\text {scid }}$ Il2rg ${ }^{\text {tm1 } 1 \text { wjl} / S z J ~(N S G) ~ m i c e ~ w e r e ~ p u r c h a s e d ~}$ from The Jackson Laboratory (Bar Harbor, ME) and bred and kept in filter top cages at $22^{\circ} \mathrm{C}, 60 \%$ humidity in our facility. Sterile food and water were accessible ad lib. TJU-UM001 cells were implanted in the liver or spleen in both male and female 8- to 10-week-old mice and kept in the same conditions.

\section{Tumor Implantation}

Exploratory experiments to decide the route of implantation of TJU-UM001 cells showed that this cell line does not grow if implanted subcutaneously or injected intravenously. This triggered the development of the following two direct implantation methods.

\section{Direct Hepatic Implantation Model}

Each mouse was anesthetized before surgery with 3\% isoflurane for induction and $2 \%$ for maintenance on a heated pad (no. 1060; K\&H Manufacturing Inc., Colorado Springs, CO) in the supine position. A $1.5-\mathrm{cm}$ abdominal incision was made in the left subcostal area so that the left lobe of the liver could be exposed easily. Then, a wire retractor (14130; World Precision Instruments, Sarasota, FL) was inserted inside the peritoneum, and the surface of the liver was exposed. If exposure of the liver was not enough, the falciform ligament that attaches to the diaphragm and the abdominal wall was cut to easily mobilize the liver. TJU-UM001 cells in $20 \mu \mathrm{L}$ of RPMI 1640 mixed with BD Matrigel Matrix HC (354248; BD Biosciences, Bedford, MA) (mixing ratio is 2:1) were drawn into a Hamilton syringe (7655-01; Hamilton Company, Reno, $\mathrm{NV}$ ) with a 27-guage needle cutting at a 12-degree angle (7803-01; Hamilton Company) and injected directly under the surface of the left lobe of the liver through the abdominal incision. To prevent the leakage of cell suspension and bleeding, the insertion site of the needle in the liver was cauterized with surgical cautery (22-101; McKesson, San Francisco, CA). The abdominal incision was closed in two 
Table 3 Comparison of the Size of Hepatic Tumor in the Implantation Site between Different Groups of Cell Number

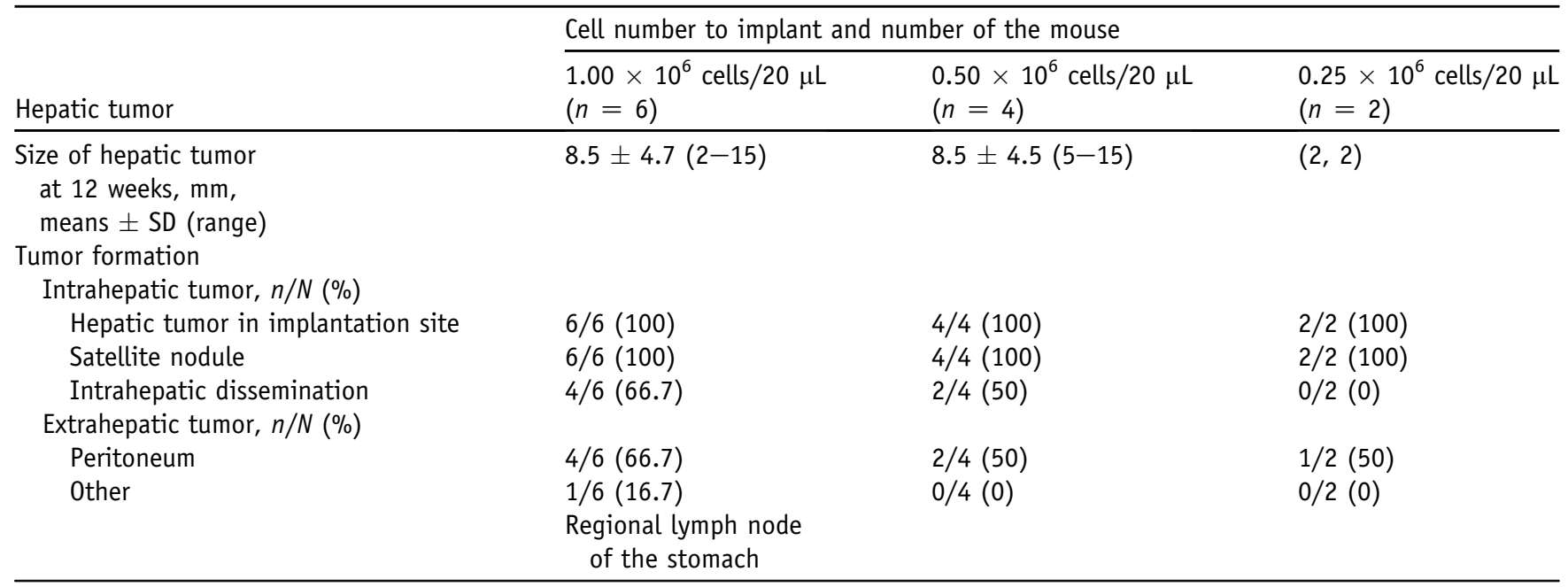

layers with 5-0 Vicryl Plus (VCP493G; Ethicon, Inc., Somerville, NJ). Postoperatively, mice were kept warm with a heater and returned to their cages when they became fully awake.

\section{Splenic Implantation Model}

Under anesthesia as described in the section above, mice were set in the right lateral recumbent position. A $1.5-\mathrm{cm}$ incision was made in the left lower abdominal wall, and the wire retractor was inserted inside the abdominal wall to expose the spleen. TJU-UM001 cells mixed with BD Matrigel Matrix HC were implanted under the surface of the spleen with the same method as that of the direct hepatic implantation model. Insertion site of the needle was cauterized, and the abdominal incision was closed in two layers as described in the section above. Postoperatively, mice were kept warm with a heater and returned to their cages when they became fully awake.

\section{Evaluation of Liver Tumor Development}

Direct Hepatic Implantation Model

To determine optimal cell number for tumor implantation for tumor development in the mouse liver, we tested different cell numbers $\left(0.25 \times 10^{6}, 0.50 \times 10^{6}\right.$, and $\left.1.00 \times 10^{6}\right)($ Table 2$)$. Mice were euthanized at 12 weeks, and livers were removed. In a different experiment, mice were euthanized at different time points $(4,8$, and 12 weeks) after implantation of $1.00 \times 10^{6}$ tumor cells (Table 3 ). A complete autopsy was performed on each mouse, and the tumor invasion and dissemination were identified by gross and histologic examinations. For the liver specimens, the maximum sections of the main tumor in the left lobe and liver parenchyma of left and right lobes were examined to investigate the formation of satellite nodule, vascular invasion in the main tumor, and intrahepatic dissemination in the different segments of the liver at different time courses by
H\&E staining. For the satellite nodule, vessel invasion, and intrahepatic dissemination, each event was defined as follows: satellite nodule, small tumor lesions being adjacent to but not abutting the main tumor; vessel invasion, intraluminal tumor cells, invasion of tumor cells to the vessels in the maximum section of the main tumor; intrahepatic dissemination: tumor lesions found in a section of
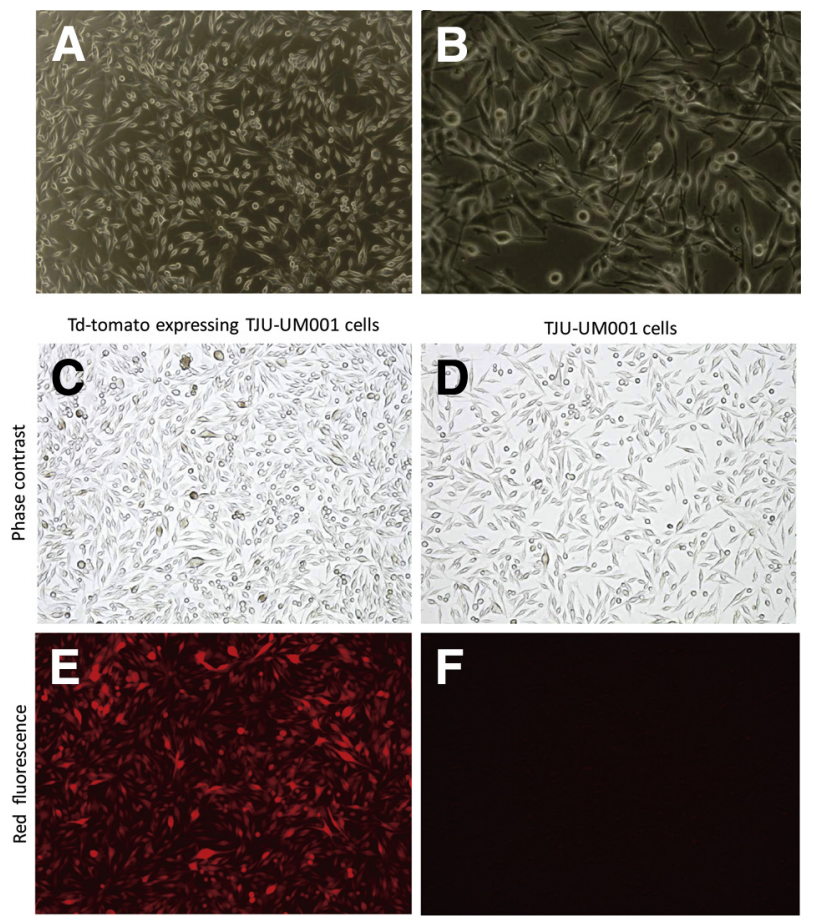

Figure 1 Structural characteristics of TJU-UM001 cells and tdTomato TJU-UM001 cells. A and B: Structural characteristics of TJU-UM001 cells in culture. C-F: Comparison between tdTomato ${ }^{+}$TJU-UM001 cells and parental cells. No substantial structural changes are observed after transfection between them (C and D). tdTomato TJU-UM001 cells express orange-red fluorescence $(\mathbf{E})$, but parental cells do not $(\mathbf{F})$. Original magnification: $\times 40(\mathbf{A}) ; \times 100(\mathbf{B}-\mathbf{F})$. 

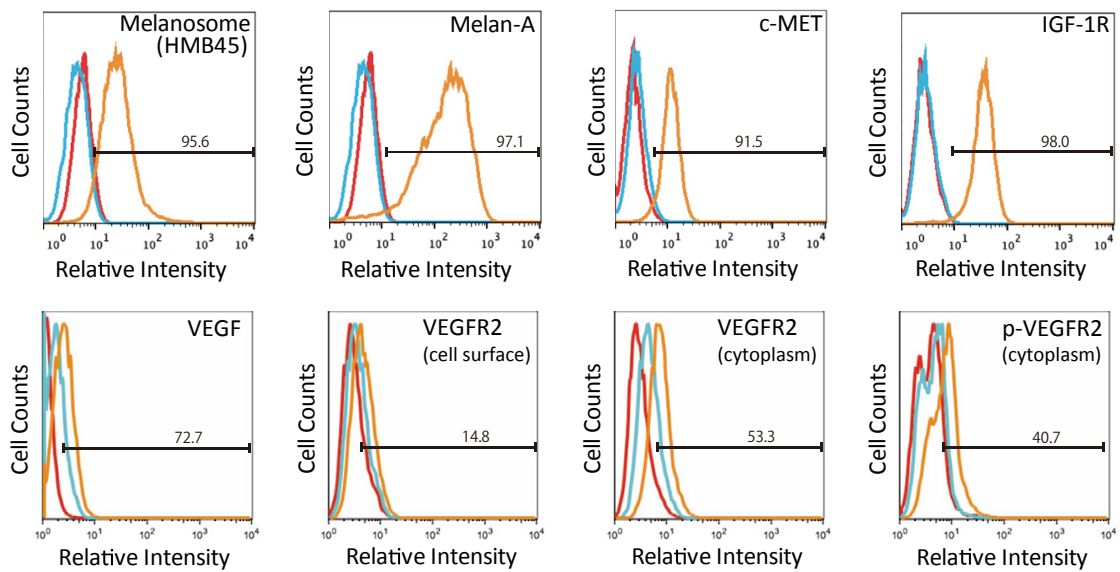

Figure 2 Flow cytometric analysis on TJU-UM001 cells, including melanoma markers, cell surface receptors, and VEGF-related molecules. IGF, insulin growth factor; VEGF, vascular endothelial growth factor. contralateral lobe to the injected lobe, $5 \mathrm{~mm}$ distant from the edge of main tumor.

\section{Splenic Implantation Model}

Mice were euthanized, and liver and spleen were extirpated at 12 weeks after implantation. An autopsy and the preparation of specimens for histologic examination were performed with the above-mentioned method. Hepatic dissemination was investigated by $\mathrm{H} \& \mathrm{E}$ and IHC staining.

\section{In Vivo Fluorescent Imaging of Liver Tumor with tdTomato-Expressing UM Cells}

tdTomato-expressing TJU-UM001 cells were implanted in NSG mice $(n=6)$ with the direct hepatic implantation method as mentioned in the sections above. In vivo fluorescence images of tdTomato were acquired with the IVIS Lumina Imaging System with DsRed filter settings (excitation filter pass band: $530 \mathrm{~nm}$, emission filter pass band: 575 nm; Caliper Life Sciences, Hopkinton, MA; a Perkin Elmer Inc.) in anesthetized tumor-bearing mice. To eliminate the background, the fur on the upper abdomen was shaved. A region of interest was set to include the range of fluorescence in the liver tumor in the shaved area and was used to quantify the total fluorescence of the tumor during the time course (from 4 to 9 weeks). Liver was extirpated at 9 weeks after implantation, and the ex vivo images were obtained for each mouse. Extirpated tissues were used for histologic examinations with the same procedure as mentioned in the sections above.

\section{Ethics}

This study was performed in strict accordance with the recommendations in the Guide for the Care and Use of Laboratory Animals of the National Institutes of Health. ${ }^{22}$ The protocol was approved by the Institutional Animal
Care and Use Committee of the Thomas Jefferson University.

\section{Results}

\section{TJU-UM001 Cells and Establishment of tdTomato TJU-UM001 Cells}

Most of TJU-UM001 cells showed spindled-shaped structure, and some of them showed dendritic structural characteristics (Figure 1, A-D). The fluorescence signal appeared uniformly in the tdTomato TJU-UM001 cells, and the infection efficiency reached almost $100 \%$ (Figure 1, E and F). This nonsorted tdTomato-expressing UM cell line keeps the same cellular structure, surface marker expressions, and doubling time (approximately 72 hours) during our experiments.

Expression of Melanoma Markers, Growth Factors, and Growth Factor Receptors in TJU-UM001

To confirm the characterization of TJU-UM001, we checked the expression of melanoma markers, growth factors, and growth factor receptors by flow cytometric analysis. Flow cytometric analysis showed that HMB45, Melan-A, c-MET, and IGF-1R are expressed in $95.6 \%, 97.1 \%, 91.5 \%$, and $98.0 \%$ in TJU-UM001 cells, respectively. For VEGF-related proteins, VEGF, VEGFR2 (cell surface), and VEGFR2 (cytoplasm) are expressed in $72.7 \%, 14.8 \%$, and $53.3 \%$ in the cells, respectively. Phospho-VEGFR2 (cytoplasm) is observed in $40.7 \%$ (Figure 2).

Tumor Formation in the Liver and Histologic Findings

\section{Direct Hepatic Implantation Model}

First, we analyzed hepatic colonization by directly implanting $\mathrm{UM}$ cells into the liver. We implanted $1.00 \times 10^{6}$ TJU-UM 001 cells directly to the liver. Macroscopic and microscopic 
External surface of the total liver

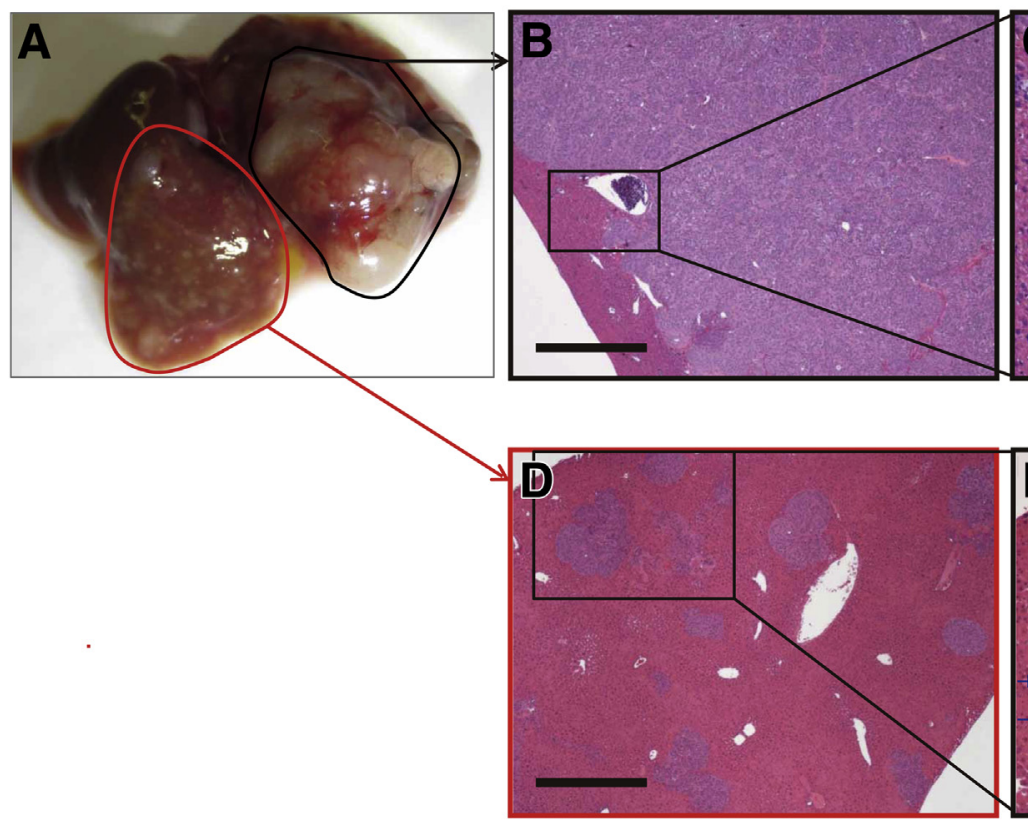

H\&E staining
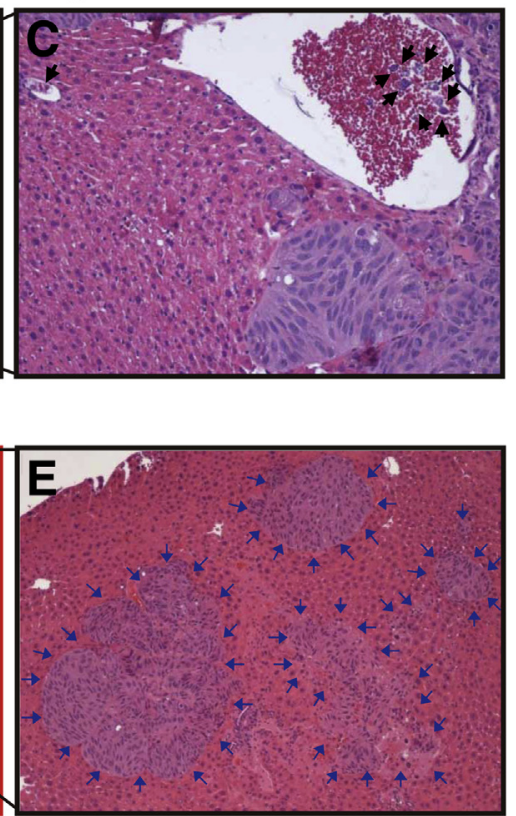

Figure 3 Macroscopic and microscopic findings of liver tumor formation in a representative case of direct hepatic implantation model. A: Twelve weeks after implantation of tumor cells to the left lobe (black outline). Multiple small intrahepatic metastases are also seen (red outline). B and C: Microscopic findings of implanted site of tumor. Infiltrating tumor cells are observed in vessels (black box, B, and black arrows, C). D and E: Intrahepatic nodules are observed in liver parenchyma (insulin growth factor; D). Multiple foci of intrahepatic metastases (blue arrows, E) exist. H\&E staining. Scale bar $=500 \mu \mathrm{m}$. Original magnification: $\times 40($ B and D); $\times 200($ C and E). H\&E, hematoxylin and eosin.

evaluations showed the development of localized tumor that measured $2 \mathrm{~mm}$ in maximum diameter in the implanted site at 4 weeks after implantation (Table 2). The implanted tumors grew to reach to the size of $7.8 \pm 4.6 \mathrm{~mm}$ in 8 weeks and $8.5 \pm 4.7 \mathrm{~mm}$ in 12 weeks, respectively (Table 2 and Figure $3 \mathrm{~A})$. We also investigated the number of tumor cells for successful growth of liver tumors. All mice developed tumor in the liver after direct implantation of $0.25 \times 10^{6}$ to $1.00 \times 10^{6}$ TJU-UM 001 cells (Table 3 ); however, the sizes of implanted tumors reached only 2 $\mathrm{mm}$ after implantation of $0.25 \times 10^{6}$ cells in 12 weeks. On the basis of these observations, we concluded that an implant of $>0.5 \times 10^{6}$ cells and 8 weeks of observation are ideal for successful development of a hepatic tumor. In this series of experiments, only one mouse died of intestinal obstruction 1 week after surgery. Other mice had no postoperative complications; thus, the postoperative mortality rate was low $(4.8 \% ; 1$ of 21$)$.

In mice that were implanted with $1.00 \times 10^{6}$ tumor cells $(n=6)$, satellite nodules and intrahepatic dissemination were observed at a rate of $100 \%$ (6 of 6) and $66.7 \%$ (4 of 6), respectively, at 12 weeks (Table 2). Furthermore, extrahepatic metastasis, including peritoneal tumors and regional lymph node metastasis, were found in $83.3 \%$ (5 of 6) of mice after 12 weeks. In one case, a 1-mm focus of metastasis was seen in a gastric lymph node located in the omentum under the stomach body. In contrast, lung metastasis was not identified in any of these mice at the time of autopsy at 12 weeks. In the tumor implantation site, tumor cells both formed localized solid tumors and infiltrated into the vessels and formed tumor thrombi (Figure 3, $\mathrm{B}$ and $\mathrm{C}$ ). In mice that showed intrahepatic dissemination, various sizes of intrahepatic lesions were seen in the sinusoid and liver parenchyma with replacement of the normal liver (Figure 3, D and E). IHC analysis showed the expression of melanoma markers (HMB45, Melan-A, and S100) in implanted tumors (Supplemental Figure S1, B-D). Furthermore, hepatic tumor cells strongly expressed cell surface growth receptors (c-Met and IGF-1R) and their phosphorylation was also observed (Supplemental Figure S1, E-H).

For tumor neovascularization, blood vessels positive for endothelial marker (CD31) specific for human and mouse vessels were observed in the hepatic tumors and in the peritumoral mouse liver (Figure 4, A, B, D and E). In addition, broad regions of extracellular matrix deposition connect the blood vessels lined by human endothelium laminin (Figure 4, C and F) and contain red blood cells (Figure 4F). These capillary-like structures are negative for vascular marker (CD31) and positive for human laminin (Figure 4, C and F). To further investigate tumor-induced angiogenesis, we stained tumor specimens with antibodies against VEGF, VEGFR 2, and phospho-VEGFR2. Greater than 90\% of UM tumor cells were strongly positive for VEGF, VEGFR2, and phospho-VEGFR2, which supported the presence of the feed-forward (positive feedback) loop in this tumor model (Figure 4, G-I). ${ }^{23}$ 

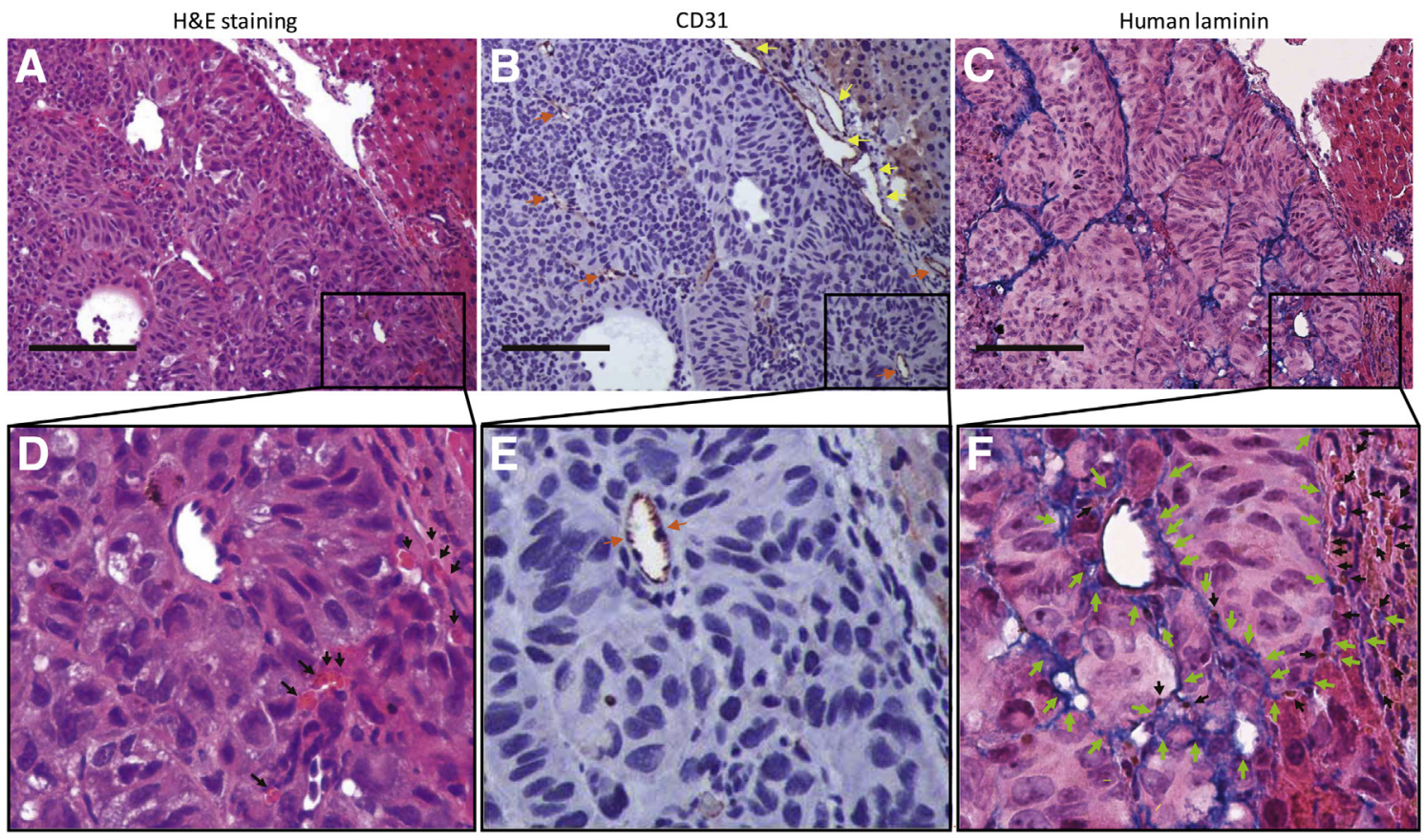

VEGF

VEGFR2
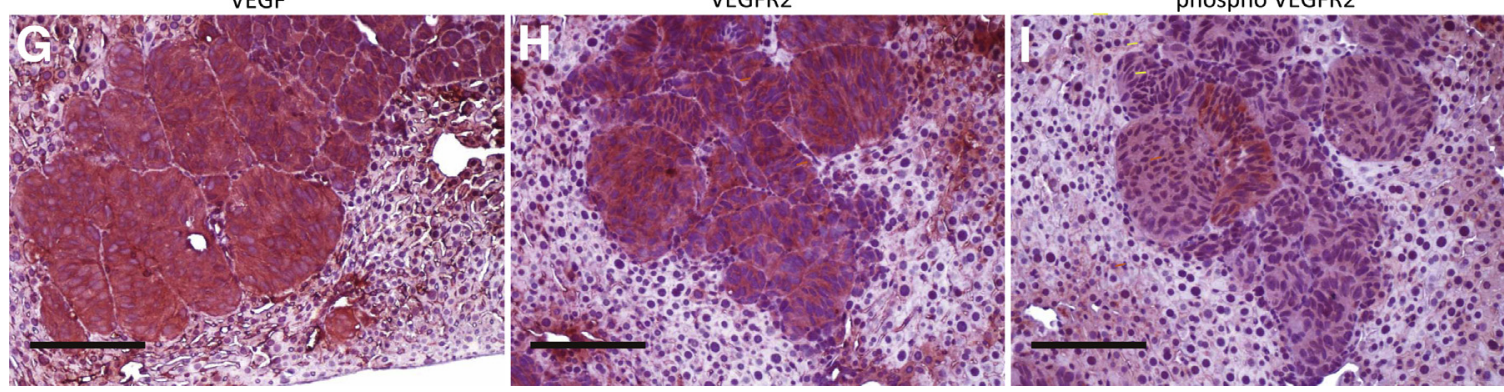

Figure 4 Immunohistochemical analysis of tumor vascularization. A-F: Tumor formation in the hepatic parenchyma (A). Immunostaining for CD31 are recognized on the normal vessels in the hepatic parenchyma (yellow arrows, $\mathbf{B}$ and $\mathbf{E}$ ) and on the neovascularization in the tumor (orange arrows, $\mathbf{B}$ and $\mathbf{E}$ ). Immunostaining for human laminin shows a blue product confined to the broad extracellular matrix consists of capillary-like structures in the tumor (C and $\mathbf{F})$. The capillary-like structures positive for human laminin (green arrows) communicate with the neovascular vessel (orange arrows) lined by endothelium (E and $\mathbf{F}$ ). The capillary-like laminin structures contain red blood cells (black arrows, F). G-I: Immunostaining for vascular endothelial growth factor, VEGFR2, and phosphor-VEGFR2. VEGF, VEGFR2, and phosphor-VEGFR2 are mainly stained in the cytoplasm of the tumors and sinusoidal endothelia of the liver. H\&E staining and immunohistochemical staining. Scale bar $=100 \mu \mathrm{m}$. Original magnification: $\times 100(\mathbf{A}-\mathbf{C}$ and $\mathbf{G}-\mathbf{I}) ; \times 400(\mathbf{D}-\mathbf{F})$. H\&E, hematoxylin and eosin; VEGF, vascular endothelial growth factor; VEGF2, vascular endothelial growth factor receptor 2.

\section{Splenic Implantation Model}

In mice that were implanted with TJU-UM-001 cells into the spleen, implanted tumors reached the size of $2 \mathrm{~cm}$ in the spleen at the conclusion of experiments in 12 weeks. Macroscopic and microscopic examinations showed multiple hepatic metastases in various sizes (Figure 5, A-C). According to the microscopic findings, small clusters of tumor cells reside in sinusoids at first and form microscopic tumor foci (Figure 5, D and E). Subsequently, the tumor cells form a larger cluster and infiltrate the hepatic parenchyma (Figure 5, F and G). Eventually the tumor cells occupy the hepatic lobule (Figure 5, H and I). IHC analysis of the tumors showed the same findings as those in the direct hepatic implantation model for melanoma markers, cell surface receptors, and vascularization. For neovascularization, compared with formation of blood vessels positive for CD31 (Figure 6, B, D, F, and H) that are only seen in larger tumors, human laminin was observed broadly in the tumor from the beginning of cluster formation (Figure 6, A, C, $\mathrm{E}$, and G). Despite small clusters with fewer number of tumor cells (5 to 10 cells), they produced human laminin and were beginning to form a capillary-like structure in a tiny cluster (Supplemental Figure S2, A-D).

\section{Monitoring of tdTomato-Expressing TJU-UM001 Cells in Vivo}

To permit noninvasive, temporal, and quantitation analysis of the in vivo growth of UM cells in the liver, a live imaging modality is required. To this end, we established tdTomato-expressing UM cell line. After implantation of tdTomato-expressing UM cell line into the liver, the tumor growth was monitored with fluorescence imaging from 4 to 9 

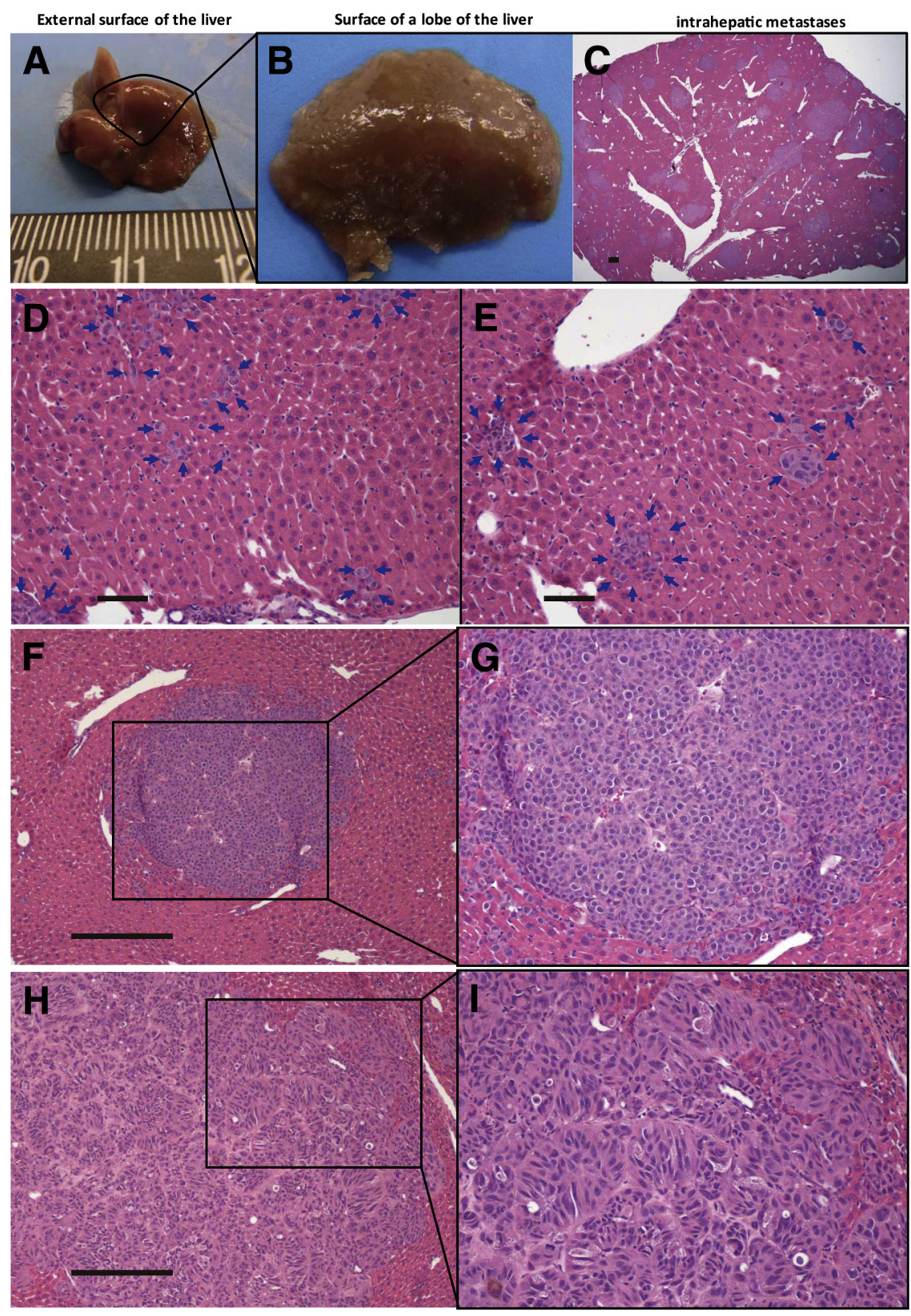

Figure 5 Macroscopic and microscopic findings of hepatic metastases in the splenic implantation model. A-C: Macroscopic findings of hepatic metastases. Nodular surface of the liver (A and $\mathbf{B}$ ) and multiple foci of metastatic nodules shown by H\&E staining (C). D-I: Microscopic findings of multiple hepatic metastases in various sizes. Avascular aggregates of the tumor cells exist in sinusoidal spaces (blue arrows, $\mathbf{D}$ and $\mathbf{E}$ ). Nodular growth of the tumor cells (F and $\mathbf{G})$. Total replacement of the hepatic lobule by the tumor cells (H and I). H\&E staining. Scale bar $=200 \mu \mathrm{m}$. Original magnification: $\times 10(\mathbf{C}) ; \times 100(\mathbf{D}, \mathbf{F}$, and H); $\times 200(\mathbf{E}) ; \times 400$ (G and I). H\&E, hematoxylin and eosin. weeks. Expression of tdTomato could be detected in the liver tumor at 4 weeks and increased during the time course (Figure 7A). Moreover, fluorescent signals could be quantified with the same region of interest with the use of Living Image software version 3.0 (PerkinElmer, Waltham, MA) (Figure 7B). A representative case is shown in Figure 7. H\&E staining showed no significant difference in tissue structure between the tumors derived from tdTomato-expressing TJU-UM001 and those of original TJU-UM001 cells (data not shown).

\section{Discussion}

Preclinical animal models are critical in the study of the molecular mechanisms directing the biological behavior of malignant tumors and the development of novel antitumor agents. Subcutaneous implantation models are used commonly because they are conventional procedures that require minimum labor. However, the microenvironment of different organs are biologically unique, ${ }^{24}$ and the data obtained from the subcutaneous tumor models might not be applicable to tumors that preferentially grow in a specific organ. To accurately assess the influence of the tumor microenvironment on tumor progression and dissemination, the interaction with stromal fibroblasts, vascular and lymphatic systems, local production of cytokines and growth factors, and the role of extracellular matrix should be considered. ${ }^{25}$ In this regard, orthotopic models of human tumors are ideal and are being used more frequently. ${ }^{10,26,27}$ For UM, the liver is the predominant site of systemic 

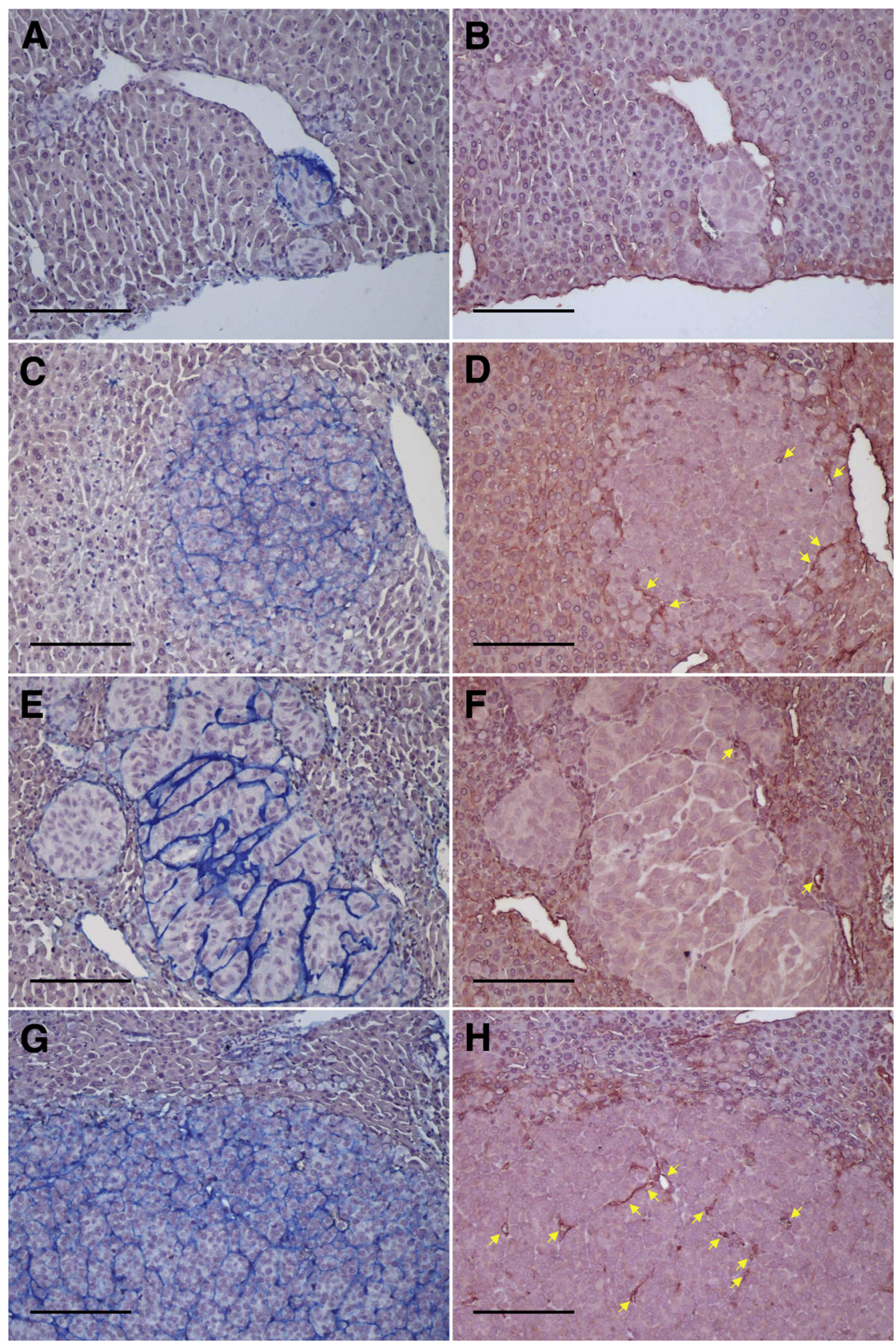

Figure 6 Immunohistochemical analysis on vascularization of hepatic metastasis in the splenic implantation model. Human laminin was observed broadly in metastatic tumor nodules regardless of the size (blue colored structures, A, C, E, and $\mathbf{G}$ ), connecting to small blood vessels positive for CD31 (yellow arrows, $\mathbf{B}, \mathbf{D}, \mathbf{F}$, and $\mathbf{H}$ ). Small cluster ( $\mathbf{A}$ and $\mathbf{B})$, middle cluster $(\mathbf{C}-\mathbf{F})$, and larger cluster ( $\mathbf{G}$ and $\mathbf{H}$ ). Immunohistochemical staining. Scale bar $=200 \mu \mathrm{m}$. Original magnification, $\times 100$. metastasis in $80 \%$ to $90 \%$ of patients with advanced disease $^{3-5}$ and suggest that the seed and soil mechanism is important in the liver. ${ }^{28}$ Thus, orthotopic hepatic metastasis and colonization models should be considered to investigate the biological behavior of the UM cells and to test novel therapies for UM in the correct tumor microenvironment.

To establish the orthotopic models, we selected a human UM cell line originated from a human hepatic metastasis (TJU-UM001) implanted into NSG mice. TJU-UM001 has typical characteristics of human UM, including a GNAQ mutation and the expression of c-Met and IGF-1 receptors on the surface of tumor cells. ${ }^{20}$ GNAQ gene encodes a heterotrimeric GTP-binding protein $\alpha$-subunit that links
$\mathrm{G}$ protein-coupled receptor signaling to the mitogenactivated protein kinase pathway. Mutations in GNAQ result in constitutive activation of the mitogen-activated protein kinase pathway and appear to be critical for the development of UM. ${ }^{15}$ Moreover, TJU-UM001 expresses cMet and IGF-1R (Figure 2). It was reported that c-Met and IGF-1R are expressed in $12.5 \%$ to $86 \%$ and $20 \%$ to $73 \%$ of primary UM specimens, respectively, and their expression is correlated with an increased risk of developing liver metastases and increased mortality. ${ }^{29-33}$ The ligands of these two receptors, HGF and IGF, are produced in high quantities in the liver and may be associated with a high propensity to develop hepatic metastases. ${ }^{34-36}$ Notably, our 


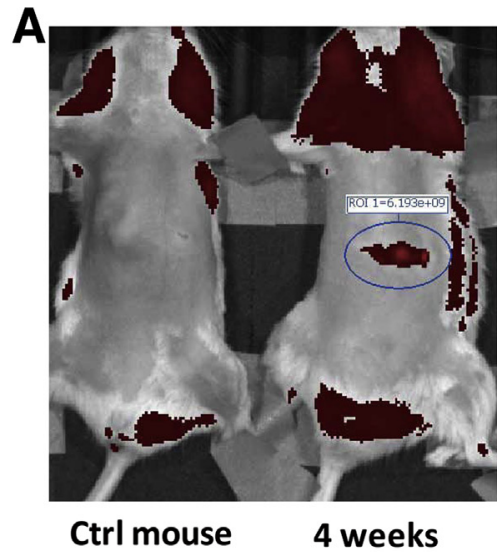

Ctrl mouse
4 weeks

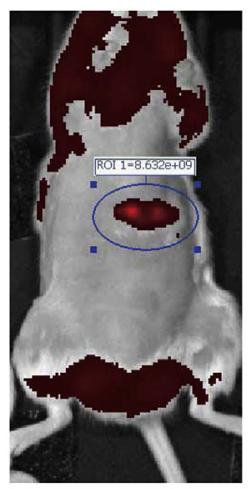

5 weeks

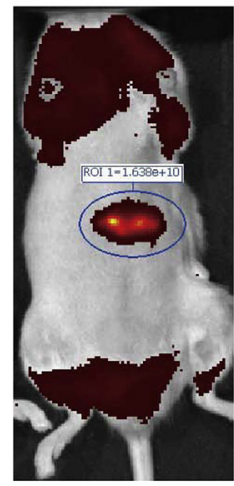

6 weeks

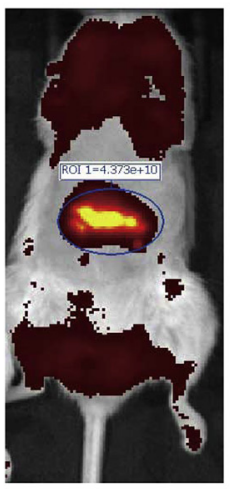

8 weeks

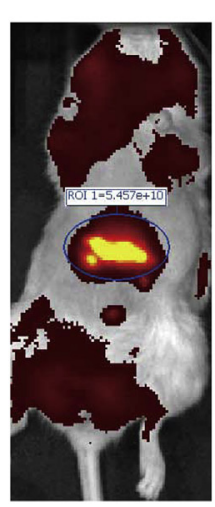

9 weeks

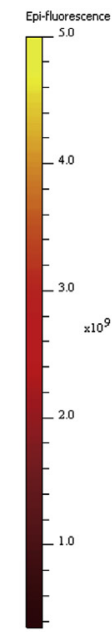

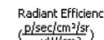

B

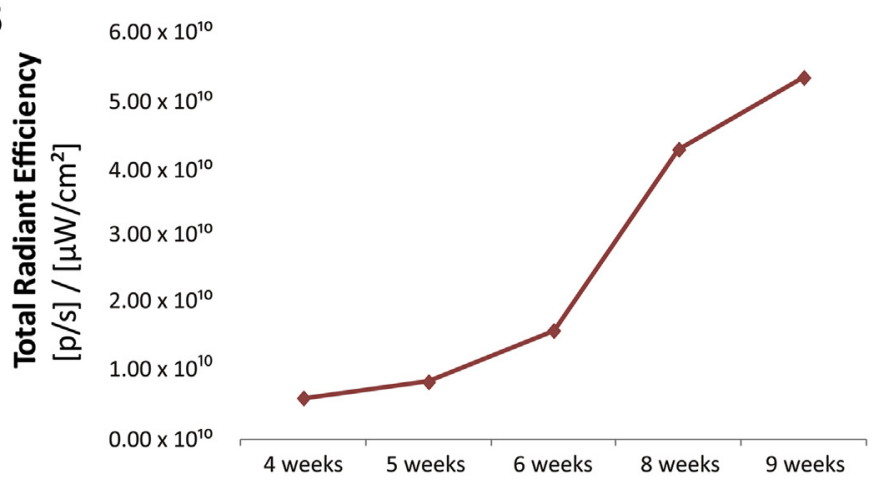

C

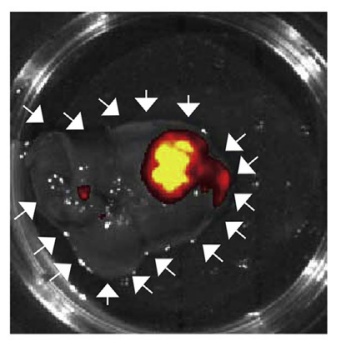

9 weeks

Ex vivo image

\section{Weeks after implantation}

Figure 7 In vivo and ex vivo imaging of tdTomato-expressing TJU-UM001 cells in the mouse liver. A-C: In vivo and ex vivo images from a representative hepatic tumor-bearing mouse are shown. The result of in vivo imaging $(\mathbf{A})$ is consistent with ex vivo image (C, white arrows) that showed positive activity in the implanted tumor and satellite lesions. tdTomato fluorescent protein in the liver tumor was detected in 4 weeks by in vivo imaging system, and radiant efficiency increased as the tumor grew (B). Color scale in A, Min $=3.5 \times 10^{8} ;$ Max $=5.00 \times 10^{9}$. Ctrl, control.

IHC staining of clinical samples obtained from UM hepatic metastasis with the use of anti-c-Met $(n=22)$ and antiIGF-1R $(n=24)$ antibody showed positive results in all tested specimens, in which $80 \%$ to $95 \%$ of UM cells were positive for c-Met (unpublished data) and $40 \%$ to $99 \%$ of $\mathrm{UM}$ cells were positive for IGF-1R, ${ }^{20}$ respectively, although these receptors were not detected in adjacent normal liver specimens. These data suggest the important role of HGF/cMet and IGF/IGF-1R interaction in UM hepatic metastasis.

For the strain of mouse, we have chosen NSG mice that lack T, B, and natural killer cells, ${ }^{37}$ which is an important factor in allowing a xenograft to grow and establish a stable model that can be used for further experimental treatments. Because mouse HGF does not bind to human c-Met receptor, ${ }^{38,39}$ c-Met-dependent growth might not be seen if UM melanoma cells lack the autocrine stimulation mechanism. In this regard, we can still use TJU-UM001 cells in this mouse model because this human UM cell line produces a small quantity of HGF in an autocrine fashion. Furthermore, c-Met pathway could be activated via crosstalk with other receptors such as the epidermal growth factor receptor
(EGFR) family or cooperation with various cell surface proteins $^{40}$; thus c-Met receptor expression might be an essential component in pathway activation. In our mouse models, phosphorylation of c-Met was actually observed; thus, autocrine production of HGF and crosstalk with other receptors might associate with this activation of c-Met (Supplemental Figure S1). Nevertheless, we are currently working on another model with the use of human HGF knock-in mice (Stock Hgftm1.1(HGF)Aveo Prkdcscid/J; The Jackson Laboratory) to further investigate this concern. We are also working on other human metastatic UV cell lines to establish multiple orthotopic mouse models for drug sensitivity testing.

Because the liver is the most dominant site and tends to be the first or the only manifestation of metastasis in metastatic $\mathrm{UV}, 5$ most of the previous in vivo studies on $\mathrm{UM}$ focused on the prevention of micrometastases from the primary site in the eye to the liver. However, clinically, it is considered that undetectable micrometastatic lesions already exist in the liver at the time of initial diagnosis and treatment of the primary UM. In fact, circulating tumor cells were detected in blood samples from UM patients having no 
clinically detectable metastatic disease at initial diagnosis or many months to years after resection of the primary site. ${ }^{41-43}$ After a period of dormancy, these melanoma cells would be detected clinically. ${ }^{1}$ For these reasons, we focused on the development of UM tumor in the liver, rather than investigating the mechanism of tumor escape from the eye. To investigate tumorgenesis in the liver, we developed two different tumor-bearing mouse models: direct hepatic implantation model and splenic implantation model. The direct hepatic implantation model was designed to investigate the intrahepatic progression of UM metastasis, whereas the splenic implantation model was developed to investigate the mechanism of hematogenous metastasis of UM cells in the liver. UM tumor developed in the spleen send tumor cells exclusively to the liver via the portal vein. This would be a better model, compared with intraocular injection of UM cells, in which the number of tumor cells passing through the lung circulation would be limited and unpredictable.

According to a recent study on pathologic findings on liver samples obtained at autopsy from patients who succumbed to UM hepatic metastases, the following hepatic colonization model was proposed: UM cells first flow into the sinusoid via the hepatic artery or the portal vein and reside there at first, they subsequently start to grow, invade the liver parenchyma, and eventually replace a hepatic lobule. ${ }^{44,45}$ Interestingly, the findings of hepatic metastases in our two mouse models are consistent with the above clinical observation. Therefore, these mouse models recapitulate the steps of metastatic tumor growth in the liver as demonstrated in the clinical setting of UM hepatic metastases. In addition, in our mouse models, tumors in other sites, including lung and brain, could not be identified macroscopically and microscopically at 12 weeks after implantation. This result is also consistent with the relatively slow progression of UM metastasis in other organs in the clinical setting. Furthermore, subcutaneously implanted TJU-UM001 cells did not grow with the same number of cells as being used in these two orthotopic models (data not shown). Therefore, it is conceivable that suitable tumor microenvironment is essential for UM cells to take up residence and a crosstalk between the melanoma cells and their surrounding tissue, or tumor stroma would be an important determining factor for their growth.

In contrast to the slow growth of UV in nonhepatic sites, we tend to see the peritoneal dissemination and regional lymph node metastases in patients with hepatic metastases after the successful control of hepatic metastasis with liverdirected treatments such as immunoembolization and chemoembolization. This, again, is consistent with the findings observed in our direct hepatic implantation model, including intra-abdominal, extrahepatic metastasis such as peritoneal tumors and a regional lymph node metastasis. The regional lymph node metastasis indicates dissemination of tumor cells via the lymph channels from the liver. The development of peritoneal tumors might be because of an anatomic characteristic of mouse, in which the surface of the liver is always adjacent to the peritoneum. Actually, in our preliminary experiments, some of the liver tumors inoculated under the hepatic capsule directly invaded into the peritoneum at 12 weeks after implantation. Similar findings were observed at our institution in a limited number of UM patients who had core biopsy or ablative treatment of hepatic metastasis (unpublished observation).

As for the neovascularization, broad extracellular matrix lined by human laminin was observed with the growth of the tumor (Figure 4, C and F and Figure 6, A, C, E, and G). This matrix pattern lined by laminin is called vasculogenic mimicry (VM) and is recognized as one of the characteristics of UM likely to develop metastasis. ${ }^{46}$ This microcirculation characteristics of VM was first described in $\mathrm{UM}^{46,47}$ and then reported in cutaneous melanoma, breast, lung, colon, and liver cancers and sarcomas. ${ }^{48}$ Moreover, VM formation in such cancers is substantially associated with metastasis and poor prognosis. ${ }^{46,49}$ As for the VM formation in UM xenograft models, it was previously reported in four animal models: two orthotopic models for primary site, one orthotopic model for hepatic metastases, and one heterotopic (subcutaneous) model. ${ }^{50-53}$ In our orthotopic models for hepatic metastases, the structures of VM were lined with human UM cells and rich in human laminin, indicating that these laminins are produced by the human UM cells. The findings are consistent with a previous report. ${ }^{52}$ Furthermore, VM in our mouse models has connections with vessels lined with endothelium and contain many red blood cells in these networks (Figure 4F). Thus, microcirculation might exist inside the VM and contribute to the tumor development and intrahepatic dissemination as previously reported. ${ }^{54,55}$ Notably, even small numbers of tumor cells in the liver begin to form VM (Supplemental Figure S2, A-D) and eventually develop a broad network of VM as the tumor grows (Figure 6, A, C, E, and G). Thus, VM might contribute to the microcirculation in the tumor preceding development of vessels lined with endothelium. These findings indicate that vasculogenic mimicry is intrinsic to the formation of metastasis in the liver. Some important signaling pathways and the associated genes related to VM were reported. In particular, critical VM-modulating genes can be categorized into vascular, embryonic, and/or stem cell, and hypoxia signaling pathways. ${ }^{56}$ Experimental evidence was reported for inhibitory effects on these specific pathways in vitro and in vivo with the use of plant-derived compounds (genistein and curcumin) or medications approved by the U.S. Food and Drug Administration (thalidomide and rapamycin). ${ }^{57-60}$ Therefore, targeting VM has the potential to inhibit UM development. Moreover, VEGF and VEGFR2 were expressed at the rate of $>90 \%$ of UM cells in our study, and phosphoVEGFR 2 was also expressed mainly in the cytoplasm of these tumor cells in vitro and in vivo (Figure 4, G-I). This result indicates the existence of an autocrine feed-forward loop in VEGF/VEGFR2 signaling in TJU-UM001 cells as reported in different types of cancer. ${ }^{22,61}$ In fact, studies 
showed that most UM cell lines and primary tumor material from UM patients express VEGF to various extents. ${ }^{62,63}$ Besides, some cell lines expressed not only VEGF but also VEGFR2 in culture, and VEGFR2 is activated in both a paracrine and an autocrine fashion. ${ }^{64}$ Furthermore, serum VEGF concentrations correlated with the size and angiogenesis of primary UM and development of hepatic metastasis. ${ }^{65,66}$ Therefore, VEGF/VEGFR2 signaling plays a key role in the establishment and progression of UM and the inhibition of this signaling might be an effective treatment strategy for UM. This concept could be tested in our mouse models.

Taken together, our orthotopic tumor-bearing mouse models for human UM hepatic metastasis recapitulated the clinical process of UM tumor growth, metastasis formation, and tumor angiogenesis in the liver. Furthermore, we successfully introduced tdTomato gene to the parental metastatic UM cell line and achieved a noninvasive fluorescence imaging system for UM hepatic metastasis (Figure 7), which allows live monitoring of tumor growth. The findings obtained from these mouse models are similar to those observed in a clinical setting; thus, these models are useful for the investigation of the biology of UM tumor in the liver and can be used for development of novel therapies that target hepatic metastases. We recently published in vitro data on combination treatments with the use of a mitogen-activated protein extracellular signalrelated kinase kinase inhibitor and c-Met or ERBB3 blockades on metastatic UV. ${ }^{67} \mathrm{We}$ are currently designing preclinical studies with the use of the orthtopic metastasis models presented in this article.

\section{Supplemental Data}

Supplemental material for this article can be found at http://dx.doi.org/10.1016/j.ajpath.2015.09.011.

\section{References}

1. Blanco PL, Lim LA, Miyamoto C, Burnier MN: Uveal melanoma dormancy: an acceptable clinical endpoint? Melanoma Res 2012, 22: $334-340$

2. Singh AD, Bergman L, Seregard S: Uveal melanoma: epidemiologic aspects. Ophthalmol Clin North Am 2005, 18:75-84. viii

3. Collaborative Ocular Melanoma Study Group: Assessment of metastatic disease status at death in 435 patients with large choroidal melanoma in the Collaborative Ocular Melanoma Study (COMS): COMS report no. 15. Arch Ophthalmol 2001, 119:670-676

4. Kujala E, Makitie T, Kivela T: Very long-term prognosis of patients with malignant uveal melanoma. Invest Ophthalmol Vis Sci 2003, 44: 4651-4659

5. Sato T, Han F, Yamamoto A: The biology and management of uveal melanoma. Curr Oncol Rep 2008, 10:431-438

6. Kath R, Hayungs J, Bornfeld N, Sauerwein W, Hoffken K, Seeber S: Prognosis and treatment of disseminated uveal melanoma. Cancer 1993, 72:2219-2223

7. Hsueh EC, Essner R, Foshag LJ, Ye X, Wang HJ, Morton DL: Prolonged survival after complete resection of metastases from intraocular melanoma. Cancer 2004, 100:122-129

8. Gragoudas ES, Egan KM, Seddon JM, Glynn RJ, Walsh SM, Finn SM, Munzenrider JE, Spar MD: Survival of patients with metastases from uveal melanoma. Ophthalmology 1991, 98: 383-389; discussion 390

9. Bedikian AY: Metastatic uveal melanoma therapy: current options. Int Ophthalmol Clin 2006, 46:151-166

10. Cespedes MV, Casanova I, Parreno M, Mangues R: Mouse models in oncogenesis and cancer therapy. Clin Transl Oncol 2006, 8:318-329

11. Mueller MM, Fusenig NE: Friends or foes - bipolar effects of the tumour stroma in cancer. Nat Rev Cancer 2004, 4:839-849

12. Beadling C, Jacobson-Dunlop E, Hodi FS, Le C, Warrick A, Patterson J, Town A, Harlow A, Cruz F 3rd, Azar S, Rubin BP, Muller S, West R, Heinrich MC, Corless CL: KIT gene mutations and copy number in melanoma subtypes. Clin Cancer Res 2008, 14:6821-6828

13. Davies H, Bignell GR, Cox C, Stephens P, Edkins S, Clegg S, et al: Mutations of the BRAF gene in human cancer. Nature 2002, 417:949-954

14. Rimoldi D, Salvi S, Lienard D, Lejeune FJ, Speiser D, Zografos L, Cerottini JC: Lack of BRAF mutations in uveal melanoma. Cancer Res 2003, 63:5712-5715

15. Van Raamsdonk CD, Bezrookove V, Green G, Bauer J, Gaugler L, O'Brien JM, Simpson EM, Barsh GS, Bastian BC: Frequent somatic mutations of GNAQ in uveal melanoma and blue naevi. Nature 2009, 457:599-602

16. Zuidervaart W, van Nieuwpoort F, Stark M, Dijkman R, Packer L, Borgstein AM, Pavey S, van der Velden P, Out C, Jager MJ, Hayward NK, Gruis NA: Activation of the MAPK pathway is a common event in uveal melanomas although it rarely occurs through mutation of BRAF or RAS. Br J Cancer 2005, 92:2032-2038

17. Iwamoto S, Burrows RC, Grossniklaus HE, Orcutt J, Kalina RE, Boehm M, Bothwell MA, Schmidt R: Immunophenotype of conjunctival melanomas: comparisons with uveal and cutaneous melanomas. Arch Ophthalmol 2002, 120:1625-1629

18. Iwamoto S, Burrows RC, Kalina RE, George D, Boehm M, Bothwell MA, Schmidt R: Immunophenotypic differences between uveal and cutaneous melanomas. Arch Ophthalmol 2002, 120:466-470

19. Harbour JW, Onken MD, Roberson ED, Duan S, Cao L, Worley LA, Council ML, Matatall KA, Helms C, Bowcock AM: Frequent mutation of BAP1 in metastasizing uveal melanomas. Science 2010, 330:1410-1413

20. Yoshida M, Selvan S, McCue PA, Deangelis T, Baserga R, Fujii A, Rui H, Mastrangelo MJ, Sato T: Expression of insulin-like growth factor-1 receptor in metastatic uveal melanoma and implications for potential autocrine and paracrine tumor cell growth. Pigment Cell Melanoma Res 2014, 27:297-308

21. Abel EV, Aplin AE: FOXD3 is a mutant B-RAF-regulated inhibitor of G(1)-S progression in melanoma cells. Cancer Res 2010, 70:2891-2900

22. Committee for the Update of the Guide for the Care and Use Laboratory AnimalsNational Research Council; Guide for the Care and Use of Laboratory Animals: Eighth Edition. Washington, DC, National Academies Press, 2011

23. Chatterjee S, Heukamp LC, Siobal M, Schottle J, Wieczorek C, Peifer M, Frasca D, Koker M, Konig K, Meder L, Rauh D, Buettner R, Wolf J, Brekken RA, Neumaier B, Christofori G, Thomas RK, Ullrich RT: Tumor VEGF:VEGFR2 autocrine feed-forward loop triggers angiogenesis in lung cancer. J Clin Invest 2013, 123:1732-1740

24. Fidler IJ: The pathogenesis of cancer metastasis: the 'seed and soil' hypothesis revisited. Nat Rev Cancer 2003, 3:453-458

25. Joyce JA: Therapeutic targeting of the tumor microenvironment. Cancer Cell 2005, 7:513-520

26. Killion JJ, Radinsky R, Fidler IJ: Orthotopic models are necessary to predict therapy of transplantable tumors in mice. Cancer Metastasis Rev 1998-1999, 17:279-284

27. Hoffman RM: Orthotopic metastatic mouse models for anticancer drug discovery and evaluation: a bridge to the clinic. Invest New Drugs 1999, 17:343-359

28. Fidler IJ: Critical determinants of melanoma metastasis. J Investig Dermatol Symp Proc 1996, 1:203-208

29. Economou MA, All-Ericsson C, Bykov V, Girnita L, Bartolazzi A, Larsson O, Seregard S: Receptors for the liver synthesized growth 
factors IGF-1 and HGF/SF in uveal melanoma: intercorrelation and prognostic implications. Acta Ophthalmol 2008, 86 Thesis 4:20-25

30. Topcu-Yilmaz P, Kiratli H, Saglam A, Soylemezoglu F, Hascelik G: Correlation of clinicopathological parameters with HGF, c-Met, EGFR, and IGF-1R expression in uveal melanoma. Melanoma Res 2010, 20:126-132

31. Mallikarjuna K, Pushparaj V, Biswas J, Krishnakumar S: Expression of epidermal growth factor receptor, ezrin, hepatocyte growth factor, and c-Met in uveal melanoma: an immunohistochemical study. Curr Eye Res 2007, 32:281-290

32. Mallikarjuna K, Pushparaj V, Biswas J, Krishnakumar S: Expression of insulin-like growth factor receptor (IGF-1R), c-Fos, and c-Jun in uveal melanoma: an immunohistochemical study. Curr Eye Res 2006, 31:875-883

33. Abdel-Rahman MH, Boru G, Massengill J, Salem MM, Davidorf FH: MET oncogene inhibition as a potential target of therapy for uveal melanomas. Invest Ophthalmol Vis Sci 2010, 51:3333-3339

34. Nakamura T, Mizuno S: The discovery of hepatocyte growth factor (HGF) and its significance for cell biology, life sciences and clinical medicine. Proc Jpn Acad Ser B Phys Biol Sci 2010, 86:588-610

35. Le Roith D: Seminars in medicine of the Beth Israel Deaconess Medical Center. Insulin-like growth factors. N Engl J Med 1997, 336:633-640

36. Bakalian S, Marshall JC, Logan P, Faingold D, Maloney S, Di Cesare S, Martins C, Fernandes BF, Burnier MN Jr: Molecular pathways mediating liver metastasis in patients with uveal melanoma. Clin Cancer Res 2008, 14:951-956

37. Shultz LD, Lyons BL, Burzenski LM, Gott B, Chen X, Chaleff S, Kotb M, Gillies SD, King M, Mangada J, Greiner DL, Handgretinger R: Human lymphoid and myeloid cell development in NOD/LtSz-scid IL2R gamma null mice engrafted with mobilized human hemopoietic stem cells. J Immunol 2005, 174:6477-6489

38. Zhang YW, Su Y, Lanning N, Gustafson M, Shinomiya N, Zhao P, Cao B, Tsarfaty G, Wang LM, Hay R, Vande Woude GF: Enhanced growth of human met-expressing xenografts in a new strain of immunocompromised mice transgenic for human hepatocyte growth factor/scatter factor. Oncogene 2005, 24:101-106

39. Francone TD, Landmann RG, Chen CT, Sun MY, Kuntz EJ, Zeng Z, Dematteo RP, Paty PB, Weiser MR: Novel xenograft model expressing human hepatocyte growth factor shows ligand-dependent growth of c-Met-expressing tumors. Mol Cancer Ther 2007, 6: 1460-1466

40. Lai AZ, Abella JV, Park M: Crosstalk in Met receptor oncogenesis. Trends Cell Biol 2009, 19:542-551

41. Schuster R, Bechrakis NE, Stroux A, Busse A, Schmittel A, Scheibenbogen C, Thiel E, Foerster MH, Keilholz U: Circulating tumor cells as prognostic factor for distant metastases and survival in patients with primary uveal melanoma. Clin Cancer Res 2007, 13:1171-1178

42. Callejo SA, Antecka E, Blanco PL, Edelstein C, Burnier MN Jr: Identification of circulating malignant cells and its correlation with prognostic factors and treatment in uveal melanoma. A prospective longitudinal study. Eye (Lond) 2007, 21:752-759

43. Ulmer A, Beutel J, Susskind D, Hilgers RD, Ziemssen F, Luke M, Rocken M, Rohrbach M, Fierlbeck G, Bartz-Schmidt KU, Grisanti S: Visualization of circulating melanoma cells in peripheral blood of patients with primary uveal melanoma. Clin Cancer Res 2008, 14: 4469-4474

44. McCuskey RS: Morphological mechanisms for regulating blood flow through hepatic sinusoids. Liver 2000, 20:3-7

45. Grossniklaus HE: Progression of ocular melanoma metastasis to the liver: the 2012 Zimmerman lecture. JAMA Ophthalmol 2013, 131: 462-469

46. Folberg R, Rummelt V, Parys-Van Ginderdeuren R, Hwang T, Woolson RF, Pe'er J, Gruman LM: The prognostic value of tumor blood vessel morphology in primary uveal melanoma. Ophthalmology 1993, 100:1389-1398

47. Folberg R, Pe'er J, Gruman LM, Woolson RF, Jeng G, Montague PR, Moninger TO, Yi H, Moore KC: The morphologic characteristics of tumor blood vessels as a marker of tumor progression in primary human uveal melanoma: a matched case-control study. Hum Pathol 1992, 23:1298-1305

48. Cao Z, Bao M, Miele L, Sarkar FH, Wang Z, Zhou Q: Tumour vasculogenic mimicry is associated with poor prognosis of human cancer patients: a systemic review and meta-analysis. Eur J Cancer 2013, 49:3914-3923

49. McLean IW, Keefe KS, Burnier MN: Uveal melanoma. Comparison of the prognostic value of fibrovascular loops, mean of the ten largest nucleoli, cell type, and tumor size. Ophthalmology 1997, 104:777-780

50. Clarijs R, Otte-Holler I, Ruiter DJ, de Waal RM: Presence of a fluidconducting meshwork in xenografted cutaneous and primary human uveal melanoma. Invest Ophthalmol Vis Sci 2002, 43:912-918

51. Mueller AJ, Maniotis AJ, Freeman WR, Bartsch DU, Schaller UC, Bergeron-Lynn G, Cheng L, Taskintuna I, Chen X, Kan-Mitchell J, Folberg R: An orthotopic model for human uveal melanoma in SCID mice. Microvasc Res 2002, 64:207-213

52. Folberg R, Leach L, Valyi-Nagy K, Lin AY, Apushkin MA, Ai Z, Barak V, Majumdar D, Pe'er J, Maniotis AJ: Modeling the behavior of uveal melanoma in the liver. Invest Ophthalmol Vis Sci 2007, 48: 2967-2974

53. Yang H, Fang G, Huang X, Yu J, Hsieh CL, Grossniklaus HE: Invivo xenograft murine human uveal melanoma model develops hepatic micrometastases. Melanoma Res 2008, 18:95-103

54. Folberg R, Hendrix MJ, Maniotis AJ: Vasculogenic mimicry and tumor angiogenesis. Am J Pathol 2000, 156:361-381

55. Hendrix MJ, Seftor EA, Hess AR, Seftor RE: Vasculogenic mimicry and tumour-cell plasticity: lessons from melanoma. Nat Rev Cancer 2003, 3:411-421

56. Kirschmann DA, Seftor EA, Hardy KM, Seftor RE, Hendrix MJ: Molecular pathways: vasculogenic mimicry in tumor cells: diagnostic and therapeutic implications. Clin Cancer Res 2012, 18:2726-2732

57. Cong R, Sun Q, Yang L, Gu H, Zeng Y, Wang B: Effect of Genistein on vasculogenic mimicry formation by human uveal melanoma cells. J Exp Clin Cancer Res 2009, 28:124

58. Chen LX, He YJ, Zhao SZ, Wu JG, Wang JT, Zhu LM, Lin TT, Sun BC, Li XR: Inhibition of tumor growth and vasculogenic mimicry by curcumin through down-regulation of the EphA2/PI3K/MMP pathway in a murine choroidal melanoma model. Cancer Biol Ther 2011, 11:229-235

59. Zhang S, Li M, Gu Y, Liu Z, Xu S, Cui Y, Sun B: Thalidomide influences growth and vasculogenic mimicry channel formation in melanoma. J Exp Clin Cancer Res 2008, 27:60

60. Su M, Feng YJ, Yao LQ, Cheng MJ, Xu CJ, Huang Y, Zhao YQ, Jiang H: Plasticity of ovarian cancer cell SKOV3ip and vasculogenic mimicry in vivo. Int J Gynecol Cancer 2008, 18:476-486

61. Goel HL, Mercurio AM: VEGF targets the tumour cell. Nat Rev Cancer 2013, 13:871-882

62. el Filali M, Missotten GS, Maat W, Ly LV, Luyten GP, van der Velden PA, Jager MJ: Regulation of VEGF-A in uveal melanoma. Invest Ophthalmol Vis Sci 2010, 51:2329-2337

63. Notting IC, Missotten GS, Sijmons B, Boonman ZF, Keunen JE, van der Pluijm G: Angiogenic profile of uveal melanoma. Curr Eye Res 2006, 31:775-785

64. Logan P, Burnier J, Burnier MN Jr: Vascular endothelial growth factor expression and inhibition in uveal melanoma cell lines. Ecancermedicalscience 2013, 7:336

65. Missotten GS, Notting IC, Schlingemann RO, Zijlmans HJ, Lau C, Eilers PH, Keunen JE, Jager MJ: Vascular endothelial growth factor a in eyes with uveal melanoma. Arch Ophthalmol 2006, 124 : $1428-1434$

66. Barak V, Pe'er J, Kalickman I, Frenkel S: VEGF as a biomarker for metastatic uveal melanoma in humans. Curr Eye Res 2011, 36:386-390

67. Cheng H, Terai M, Kageyama K, Ozaki S, McCue PA, Sato T, Aplin AE: Paracrine effect of NRG1 and HGF drives resistance to MEK inhibitors in metastatic uveal melanoma. Cancer Res 2015, 75: $2737-2748$ 